\title{
DIGITALCOMMONS

$1-1-2016$

\section{Validity and Reliability of the Connor-Davidson Resilience Scale (CD-RISC) in Competitive Sport}

Stephen P. Gonzalez

The College at Brockport

E. Whitney G. Moore

University of North Texas, whitneymoore@wayne.edu

Maria Newton

University of Utah

Nick A. Galli

University of Utah

\section{Recommended Citation}

Gonzalez, S. P., Moore, E. W. G., Newton, M., \& Galli, N. A. (2016). Validity and reliability of the Connor-Davidson resilience scale (CD-RISC) in competitive sport. Psychology of Sport and Exercise, 23, 31-39. doi: 10.1016/j.psychsport.2015.10.005 Available at: http://digitalcommons.wayne.edu/coe_khs/57 


\section{Running Head: CD-RISC-10 IN SPORT}

Validity and Reliability of the Connor-Davidson Resilience Scale (CD-RISC) in Competitive Sport: Further Support of the 10-item Connor Davidson Resilience Scale (CD-RISC-10) by

Stephen P. Gonzalez, ${ }^{1}$ E. Whitney G. Moore, ${ }^{2}$ Maria Newton, ${ }^{3}$ \& Nick A. Galli ${ }^{3}$

${ }^{1}$ Armstrong State University, ${ }^{2}$ University of North Texas, $\&{ }^{3}$ University of Utah

Author Note

Thanks to Brooks Sports, Trail Runner Magazine, Fleet Feet Savannah, Salt Lake Running Company, Mountain Trails Foundation, and the Sports Guide Magazine for data collection assistance.

Correspondence concerning this paper should be addressed to Stephen P. Gonzalez.Email: stephengonzalez@gmail.com. 


\begin{abstract}
Objective: This study replicates and extends the work of Gucciardi and colleagues (2011) in relation to the validity of the Connor-Davidson Resilience Scale (CD-RISC; Connor \& Davidson, 2003) in sport. Three primary aims were explored: 1) Examine the factor structure and fit of three versions of the CD-RISC: the original 25-item CD-RISC, both as a 25-item five factor scale and as a 25-item unidimensional scale, and the 10-item CD-RISC-10; 2) examine gender invariance of the best fitting version of the CD-RISC; and 3) examine the validity of the best fitting CD-RISC by relating it to affect and performance anxiety in a sample of competitive American distance runners $(\mathrm{N}=409)$.

Design: Cross-sectional.
\end{abstract}

Methods: Multiple self-report questionnaires were delivered through an online medium. Results: Using confirmatory factor and item level analyses, the CD-RISC-10-item scale was psychometrically superior to the unidimensional 25-item and the five factor 25-item CD-RISC versions. The CD-RISC-10-item exhibited measurement invariance for gender, with significant configural, strong, and weak analyses. Using structure equation modeling, the CD-RISC-10-item scale moderately and positively correlated with positive affect and was inversely related to negative affect and performance anxiety, establishing convergent and divergent validity. Conclusion: The findings support Gucciardi and colleagues' 2011 findings that the CD-RISC-10 is a valid and reliable instrument to assess resilient qualities in sport.

Key Words: measurement, athletics, psychometrics, scale, instrument, adversity, runners 
Validity and Reliability of the Connor-Davidson Resilience Scale (CD-RISC) in Competitive Sport: Further Support of the 10-item Connor Davidson Resilience Scale (CD-RISC-10)

Psychological resilience, or the ability to experience adversity and adapt positively (Luthar \& Cicchetti, 2000), has been identified as a desirable characteristic for athletes and coaches in sport (Fletcher \& Sarkar, 2012; Galli \& Vealey, 2008; Hosseini \& Besharat, 2010; Gucciardi, Jackson, Coulter, \& Mallett, 2011). Unfortunately, research involving resilience in the sport context is limited (Gucciardi et al, 2011; Sarkar \& Fletcher, 2013). One reason for this deficiency is the lack of a valid and reliable construct specific measure of resilience in sport (Gucciardi et al., 2011; Sarkar \& Fletcher, 2013). Indeed, recent sport psychology researchers note that one challenge of assessing resilience is that measurements developed for populations other than athletes might not adequately assess resilience in sport settings (Sarkar \& Fletcher, 2013). Recognizing the potential of resilience research to advance the knowledge base in sport psychology and the inherent measurement limitations, our study examined the validity and reliability of the Connor Davidson Resilience Scale (CD-RISC; Connor \& Davidson, 2003), including both the original 25-item and the 10-item version (Campbell-Sills \& Stein, 2007; Gucciardi et al., 2011).

Self-report assessments of resiliency originated in the field of developmental psychology in the 1980s. Originally thought to be trait-like, resilience was first measured by Block and Block (1980) who were interested in personality development from a psychoanalytic theory perspective in young school children. Block and Block named their personality construct Ego Resiliency (ER), but ER measurement was limited in scope to stable personality features (Windle, Bennett, \& Noyes, 2011). Since Block and Block's (1980) work, contemporary 
resilience researchers agree that resilience is a dynamic process and the ability to become resilient can be learned and cultivated as opposed to a rigid personality trait (Bonanno, 2004; Kumpfer, 1999; Luthar \& Cicchetti, 2000; Masten, 2001). With a need for a self-report measure congruent with contemporary resilience theory, Connor and Davidson (2003) created the CDRISC, a 25-item measurement of resilient qualities thought to help individuals mitigate stress.

The CD-RISC was developed using constructs previously related to resilience, such as hardiness (Kobasa, 1979) and characteristics derived from the presence of protective factors found in research on resilient individuals (Lyons, 1991; Rutter, 1985). Items from the CD-RISC where tested in general and clinical populations, specifically individuals from a typical American community, primary care outpatients, general psychiatric outpatients, individuals with generalized anxiety disorders, and individuals with post-traumatic stress disorder (PTSD). The CD-RISC is comprised of five subscales (components of resilience) thought to encompass resilient qualities and behaviors in individuals who positively adapt despite adversity: personal competence and tenacity (8 items; e.g., "Even when things look hopeless, I don't give up"), trust in one's instincts and strengthening effect of stress (7 items; e.g., "Having to cope with stress can make me stronger"), accepting of change positively (5 items; e.g., "Past successes give me confidence in dealing with new challenges and difficulties"), control (3 items; e.g., "I feel in control of my life"), and spiritual influences ( 2 items; "When there are no clear solutions to my problems, sometimes fate or God can help"). Participants are instructed to indicate how much they agree with each statement as it applies to their life experience. If a situation has not happened to them, then they are to speculate how they would react. Responses to each item are on a five point Likert Type Scale (0- not at all true to 4- true nearly all the time). The range of the total scale is 0-100 with higher totals indicating greater resilience. An overall summary score 
is calculated. Researchers examining the efficacy of resilience training have utilized the CDRISC to trace resilience changes over time (Davidson, et. al., 2005), supporting validity of the instrument in an application context.

The 10-item version of the CD-RISC emerged from analyses conducted by CampbellSills and Stein (2007) while examining the psychometric structure of the original CD-RISC in multiple samples totaling over 1700 college students ( $74 \%$ female). Exploratory factor analyses (EFA) of the 25-item CD-RISC in two subsamples did not support the five factors originally proposed by Connor and Davidson. Several issues emerged, namely, inconsistent item loading across the EFAs, an item failed to load on a factor, a factor being defined by too few items, and factors being difficult to interpret because the items focused on more than one theme. This led the authors to examine shorter versions of the CD-RISC. What emerged was a unidimensional 10-item CD-RISC. A CFA analysis confirmed the construct validity of the 10 -item CD-RISC, $\chi^{2}$ $(35)=176.10, p<.001, \mathrm{RMSEA}=.050,90 \% \mathrm{CI}=.043-.057, \mathrm{CFit}=0.50, \mathrm{SRMR} .028, \mathrm{CFI}=.97$, and determinacy $=.93$ (p. 1025; Campbell-Sills \& Stein, 2007). The 10-item CD-RISC exhibited adequate internal reliability $(\alpha=.85)$. Concurrent validity was supported by the finding that resilience (measured with the 10-item CD-RISC) moderated the relationship between selfreported trauma and the expression of psychiatric symptoms. Participants rating themselves as higher in resilient qualities reported less symptomology. Campbell-Sills and Stein concluded, “... the 10-item CD-RISC measures a characteristic that differentiates individuals who are functioning well after adversity from those who are not" (p. 1026).

Further support for a shortened unidimensional version of the CD-RISC was found by Burns and Anstey (2010). The structural validity of the original 25-item five factor CD-RISC was examined by conducting a CFA in a population-based sample of 1,775 young adults in 
Australia. Findings revealed a number of large Modification Indices, items that did not suitably differentiate the factors, a problematic GFI (.858) and a substantial amount of overlap between four of the five factors. The authors conducted further statistical analyses on a unidimensional CD-RISC by using an EFA with an oblique Direct Oblimin rotation with Parallel Analysis to allow any emerging factors to correlate with one another. The results of the EFA revealed that most items loaded on a single dimension, supporting the findings Campbell-Stills and Stein (2007); however, using Parallel Analysis to extract factors and noticing a lower than desired General Fit Index (GFI), Burns and Anstey settled on a slightly longer 22-item CD-RISC. Overall, the authors concluded that the two unidimensional versions of the CD-RISC were comparable and that the brevity of the 10-item version (Campbell-Stills \& Stein, 2007) may be appealing to researchers.

Given the benefits of being resilient in sport, researchers have begun to explore the validity and reliability of the CD-RISC in athletic populations. Hosseini and Besharat (2010) are credited with the first use of the original 25-item CD-RISC in a sport context. In a sample of 139 ( $n=96$ male and $n=43$ female) Iranian athletes, the CD-RISC was used to differentiate athletes on psychological well-being and performance. Athletes with more self-reported resilience had better psychological well-being and performances than athletes with less resilience. The authors did not explore the psychometrics of the scale outside of calculating Cronbach's alpha, which was reported to be sufficient (no numerical value was provided).

In the only psychometric study of the CD-RISC in sport to date, Gucciardi and colleagues (2011) examined the original 25-item CD-RISC (both as a five dimensional scale and a unidimensional 25-item scale), the 22-item scale recommended by Burns and Anstey (2010), and Campbell-Sills and Stein's 10-item CD-RISC in a sample of adult $(n=321)$ and youth $(n=199)$ 
male and female Australian cricket athletes. Using CFAs, age variance testing, and convergent and divergent validity assessments, the 10-item version of the CD-RISC (Campbell-Sills \& Stein, 2007) was deemed the best instrument for use with athletes. Specifically, the 10-item CDRISC had better item level statistics and factor structure than all other CD-RISC versions for both adult, $\chi^{2}(35)=80.10, p=.001$, RMSEA $=.063,90 \% \mathrm{CI}=.045-.082, \mathrm{CFI}=0.947, \mathrm{TLI}=.932$, $\mathrm{IFI}=.947$, and adolescents, $\chi 2(35)=61.34, p=.001$, RMSEA $=.062,90 \% \mathrm{CI}=.035-.087$, CFI $=$ $0.948, \mathrm{TLI}=.934, \mathrm{IFI}=.949$ (p. 6). The original 25 -item, five factor and the unidimensional 22item CD-RISCs had poor model fit and exhibited poor item level analyses across adults and adolescents. These findings echo previous concerns about CD-RISC, namely poor clarity and labeling of the five factors and the use of an orthogonal rotation in the original EFA (Ahern et al. 2006). In summary, the 10 -item unidimensional CD-RISC was the only version of the CD-RISC that emerged as a reliable and valid measure of resilience in a sport population.

While Gucciardi and colleagues' study was instrumental in finding support for a psychometrically sound measure of resilience, more than one study with one sport sample is needed to support the CD-RISC-10 as an appropriate measurement of resilience in sport. The purpose of our study was to partially replicate as well as extend the work of Gucciardi and colleagues (2011). We explored the factor structure of three versions of the CD-RISC in a sample of competitive post-collegiate American long distance runners. Specifically, we examined the validity and reliability of the original 25 -item five factor CD-RISC, the 25 -item unidimensional CD-RISC, and the 10-item version of the CD-RISC supported by Campbell-Sills and Stein (2007) and Gucciardi and colleagues (2011). The 22-item scale developed by Burns and Anstey (2010) was not included in this analysis because of its poor fit to the athlete population when compared to the original and 10-item CD-RISC (Gucciardi et al., 2011). 
Furthermore, the psychometrics of the 22-item scale have yet to be replicated in studies outside of Campbell-Sills and Stein's (2007) original paper. Based on prior research (Gucciardi et al., 2011) it was hypothesized that the CD-RISC-10 would exhibit the strongest psychometric properties.

We also investigated how well the resultant best fitting CD-RISC predicted affect and performance anxiety, two hypothesized constructs associated with exhibiting resilience. This study extends current understanding by addressing three shortcomings noted by Gucciardi and colleagues (2011). Notably, a larger sample size was solicited, the association between resilience and positive adaptation was examined for validity purposes, and gender invariance testing was utilized to compliment the age invariance testing conducted by Gucciardi and colleagues (2011).

Affect and performance anxiety were included as outcomes of resilience for the present study given the strong conceptual and empirical support of these constructs (Fletcher \& Sarkar, 2012; Southwick, Ozbay, Charney, \& McEwen, 2008; Tugade, \& Fredrickson, 2007; Waugh, Tugade, \& Fredrickson, 2008) as evidence of positive adaptation, the hallmark of resilience (Lepore \& Revenson, 2006; Luthar \& Cicchetti, 2000). In sport it is theorized that positive adaptation following adversity involves coping well with anxiety (Martin-Krumm, Sarrazin, Peterson, \& Famose, 2003) as well as maintaining positive affect (Galli \& Vealey, 2008). To capture these variables, this study employed the Positive and Negative Affect Schedule (PANAS; Watson et al., 1988) and the Sport and Anxiety Scale-2 (SAS-2; Smith, Smoll, Cumming, \& Grossbard, 2006) to measure affect and performance anxiety, respectively. The PANAS includes two subscales, positive affect and negative affect, and the SAS-2 includes three subscales, somatic anxiety, cognitive anxiety (worry), and concentration disruption. It was hypothesized that the strongest version of the CD-RISC should have a strong and positive 
correlation with positive affect and a negative and strong correlation with negative affect, somatic anxiety, cognitive anxiety, and concentration disruption.

\section{Methods}

\section{Participants}

Participants were 405 (54.8\% male and $45.2 \%$ female) competitive post-collegiate long distance runners from throughout the United States of America who were at least 18 years of age $(M=34.84, S D=10.05)$. The sample was predominantly Caucasian $(92.8 \%)$, with Hispanic $(2.2 \%)$ and Asian $(1.7 \%)$ individuals also represented more than others in the sample. Participants had a mean of 10.53 years of running experience $(S D=8.73)$. In order to qualify as "competitive," participants had to have run at least three races in the past year with the minimum distance being 5,000 meters (5k) and the maximum distance being a marathon, as these race distances are some of the more contested distances in the United States. Over half of the sample self-indicated that they were generally successful in competing for an overall top five $(22.3 \%)$ or age group top five $(33.5 \%)$ placing when racing. The remaining participants $(44.1 \%)$ were not as consistently successful in placing in the top five despite reporting themselves as competitive runners. Data collection took place via online survey. Runners were recruited by contacting running stores and running clubs and requesting the survey be posted via a link to their websites.

\section{Measures}

Resilience. The Connor Davidson Resilience Scale (CD-RISC; Connor \& Davidson, 2003) was used to measure resilience. The CD-RISC (Connor \& Davidson, 2003) contains 25 items and assesses five components of resilience (see introduction for item examples and number of items per component). Participants are instructed to indicate how much they agree with statements made in each item as they apply to their life experience. If a situation has not 
happened to them, then they are to speculate how they would react. Responses are indicated on a five point Likert Type Scale $(0=$ not at all true to $4=$ true nearly all the time $)$. The range of the total scale is $0-100$ with higher totals indicating greater resilience. Consistent with past research (Hosseini \& Besharat, 2010; Gucciardi, Jackson, Coulter, \& Mallett, 2011) a sum resilience score was calculated for the analysis. The CD-RISC has demonstrated good reliability $(\alpha=.88$ and .89$)$, test-retest reliability (.87), and convergent and divergent validity in the development of the scale (Connor \& Davidson, 2003; Gucciardi et al., 2011).

Performance Anxiety. The Sport Anxiety Scale-2 (SAS-2; Smith, Smoll, Cumming, \& Grossbard, 2006) is a 15-item scale with three, five-item subscales: somatic anxiety (e.g., "My body feels tense”), worry (e.g., "I worry that I will let others down”), and concentration (e.g., "I cannot think clearly during the game"). Items are measured on a four point scale $(1=$ not at all to 4= very much). Participants were prompted in the instructions to indicate reflectively how they generally feel while racing and items were modified to reflect running (i.e, "game" was changed to "race"). Subscale responses were summed (range 3-20). Smith and colleagues reported much stronger validity and reliability for the SAS-2 in comparison to the original SAS and recommended its use for both child and adult populations (Smith et al., 2006). Cronbach's alpha for the SAS-2 in this study was .92 , with alphas ranging from .77 to .86 for the subscales. The SAS-2 subscales were used for the analysis.

Affect/Emotion. The Positive and Negative Affect Schedule (PANAS; Watson et al., 1988) was used to assess affect and emotion. The PANAS is a 20-item questionnaire that measures Positive and Negative Affect using adjectives to describe different feelings and emotions. Participants were asked in general to rate their running experience. Positive and negative affect subscales each have 10 adjectives that participants rate on a five point Likert 
scale $(1=$ very slightly or not at all to 5=extremely). Example items for positive affect include "interested and strong" and for negative affect include "distressed and irritable." Reliability was borderline acceptable, as Cronbach's alphas were .69 for positive affect and .65 for negative affect for this study.

\section{Procedures}

Upon receiving IRB approval, participants were recruited primarily from running clubs, running stores, and other running organizations. Interested athletes who met the criteria provided above were given access an online web link via Survey Monkey. All participants provided passive consent and completed the measures. Once the predetermined sample size was recruited the web link was closed. At the end of the survey, all interested participants who wished to be included in a drawing for a free pair of running shoes had their email addresses put into a hat and a winner was chosen at random.

\section{Data Analysis}

MPlus 6.11 (Muthen \& Muthen, 2014) was used to a conduct confirmatory factor analysis (CFA) on the three versions of CD-RISC instrument and to model the CD-RISC to affect/emotion and performance anxiety using structural equation modeling (SEM). CFA with Maximum Likelihood estimation was used. All other analyses (normality analyses, descriptive statistics, and demographics) were computed using SPSS 20.0 (IBM, 2012).

\section{Results}

All data were assessed for normality by examining skewness and kurtosis data, and all measures had no univariate or multivariate normality issues as seen in Q-Q plots, histograms, and Shapiro-Wilks tests. Missing data points, which were less than 8 percent of all data reported, were accounted for using Expected Maximization (Tabachnick \& Fidell, 2007). The means, 
standard deviations, and Cronbach's alphas for all the variables and subscales in this study are displayed at the bottom of Table 1. The Cronbach's alphas for most of measures and subscales

were all greater than or equal to .70 , the recommended criteria when working in early stages of research (Nunnally, 1978). The only exceptions were the PANAS subscales and the spirituality scale from the 25-item five factor CD-RISC. Thus, findings in relation to these constructs should be interpreted with some caution.

\section{Univariate Simple Comparisons}

Table 1 displays the Pearson product correlations among the factors for the various forms of the CD-RISC. All were significant and positive $(r=.57-.90)$, with the exception of the spirituality factor (see factor 5 in the five factor CD-RISC). Spirituality was nominally related to the CD-RISC-10, as well as factor 2 - strengthening effect of stress - of the five factor CD-RISC $(r=.05)$. A majority of the relationships between the factors of the versions of the CD-RISC and the outcome variables (affect and performance anxiety) were significant and in the expected direction (see Table 1). Greater resilience was related to more positive affect and less performance anxiety. Negative affect exhibited the weakest, and in most cases, non-significant, relationships with the versions of the CD-RISC. The CD-RISC-10 exhibited nominally stronger relationships in each regard. Collectively, these findings cast initial suspicion on the utility of the five factor CD-RISC and provide initial support for CD-RISC-10 as a measure of resilience in sport.

Confirmatory Factor Analyses (CFAs) of the CD-RISC

CFAs were conducted on the three variations of the CD-RISC (see the top portion of Table 2). In evaluating the fit indices for the models, the following parameters were used as recommended by Hu and Bentler (1997, 1999) and Bentler (2007): SRMR of .05 or less, TLI 
of .95 or higher, RMSEA of .05 or less, and a CFI of .95 or higher. The CD-RISC-10 met all of the above indices recommendations for relative fit (TLI), absolute fit (SRMR), and noncentrality based fit (CFI and RMSEA). In contrast, the fit indices for the five factor model and the unidimensional model did not meet any of the adequacy criteria for model fit. These findings provide initial support for the validity of the CD-RISC-10 and suggest the five factor model and the unidimensional model might not be valid in sport.

The fixed factor method was utilized to compute standardized loadings (lambdas) and error terms (thetas) for each item of the CD-RISC versions in Table 3. Of the three models, the CD-RISC-10 had the most consistency in factor loading strength, and lower or comparable error terms, compared to both the original five factor CD-RISC and the unidimensional version of the CD-RISC. These findings provide further support for the validity of the 10 -item version of the CD-RISC in sport. Because the CD-RISC-10 had the best emerging factor structure, item level analyses for this instrument were conducted (see Table 4). The CD-RISC-10 items had suitable corrected item-total correlation consistency and the Cronbach's alpha if item deleted remained consistently between .84 and .86 , demonstrating that the items were equally good indicators of resilience. Finally, the factor loadings for all the CD-RISC-10 items were moderate to high, which further supports the internal validity of the measure.

\section{Gender Invariance of the CD-RISC-10}

Gender invariance testing was conducted on the CD-RISC-10, because it emerged as the best fitting model. The purpose of this invariance testing was to confirm there was no difference in measurement functioning by gender. The two group (males and females) configural CDRISC-10 model was significant $\left(\chi^{2}=2094.25 ; p<.001\right.$; see the bottom portion of Table 2$)$. To test the loading structure of the CD-RISC-10 indicators, item loadings were equated across 
gender to attain measurement weak invariance. The CD-RISC-10 model passed the weak invariance test based upon the change in $\mathrm{CFI}(\triangle \mathrm{CFI}=.004)$. Finally, the CD-RISC-10 indicator intercepts were equated across males and females to test for strong measurement invariance. This model passed the strong invariance test, based upon the change in $\mathrm{CFI}(\Delta \mathrm{CFI}=.008)$. As a result, measurement invariance was achieved between males and females on the CD-RISC-10. Importantly, gender invariance provides further support for the validity of the CD-RISC-10. Structural Equation Model (SEM) of the CD-RISC-10 to the SAS-2 and the PANAS

To explore the predictive validity of the CD-RISC-10 it was modeled to positive and negative emotion, as well as performance anxiety (somatic, worry, and concentration disruption). It is important to note that at the configural level, three items of the negative affect subscale of the PANAS (ashamed, nervous, and jittery) exhibited poor standardized loadings. These items were removed at one time and the model fit was reevaluated. Hofmann (1995) justified this process as it retains the general hypothesized model but only with the best available indicators. The subsequent model had a good fit, $\left.\chi^{2}=3491.48, p=.001\right)$, NFI $=.96$, IFI $=.97, \mathrm{CFI}=.69$, GFI $=$ $.97, \mathrm{TLI}=.67$, and SRMSR $=.14$, and the RMSEA was acceptable at $0.08(\mathrm{Kline}, 2011)$. The regression weights and item loadings for the measures are displayed in Table 5. As expected and depicted in Figure 1, resilience predicted affect and performance anxiety $\left(R^{2}=76 \%\right)$. More specifically, greater resilience predicted less somatic anxiety $(r=-.24)$, less cognitive anxiety ( $r=$ $-.58)$, less cognitive disruption $(r=-.38)$, greater positive affect $(r=.67)$ and less negative affect $(r=-.57)$. The relationships of the CD-RISC-10 to affect and performance anxiety were as hypothesized. Collectively these findings support the validity of the CD-RISC-10. Convergent validity was established with the relationship of the CD-RISC-10 to positive affect, and 
divergent validity was established with the relationship of the CD-RISC-10 to negative affect, somatic anxiety, cognitive anxiety, and concentration disruption.

\section{Discussion}

The primary purpose of this study was to further assess the factor structures of various forms of the CD-RISC in a sample of competitive male and female distance runners. The supplemental purposes were to then test the best fitting scale's measurement properties for gender invariance and test hypothesized convergent and divergent validity. Overall, the CDRISC-10 (Campbell-Sills \& Stein, 2007; Gucciardi et. al., 2011) emerged as the most promising instrument, in comparison to the five factor CD-RISC (Connor \& Davidson, 2003) and the unidimensional CD-RISC (Connor \& Davidson, 2003). The CD-RISC-10 exhibited the best fitting factor structure, was internally reliable and invariant to the gender of the respondents. Furthermore, the resultant relationships of the CD-RISC-10 to pertinent outcome variables were consistent with resilience theory. Resilient qualities in male the female runners were able to predict a large amount of the variance in affect and performance anxiety.

The emergence of the CD-RISC-10 as the best instrument to assess resilient qualities supports previous research (Burns \& Anstey, 2010; Gucciardi et al., 2011). Our findings replicate those of Gucciardi and colleagues (2011) and support concerns raised by Ahern and colleagues (2006) in relation to the original 25 item, five factor CD-RISC. It terms of concerns, the original five factor model did not fit the data, the item-factor linkage is a bit confusing, and the existence of only two questions tapping the spirituality dimension of resilience is problematic (Ahern, Kiehl, Sole, \& Byers, 2006). Supporting the findings of Gucciardi and colleagues (2011), the CD-RISC-10 correlated quite strongly with the unidimensional model $(r=.90)$ and 
each of the five factors of the original model $(r=.57-90)$ with the exception of spirituality $(r=.05)$, suggesting a rather high degree of similarity between the measures (Gucciardi et al, 2011). In concert with previous research (Gucciardi et al, 2011) item number 6, "see the humorous side of things" exhibited the lowest loading (.459) on CD-RISC-10. However, the item exhibited a stronger loading in our study than reported in Gucciardi and colleagues' (2011) research (.34/.31). Furthermore, the reliability findings (corrected item-total correlation and alpha if item deleted) supported the integration of the item. Optimism and positive emotions are important components of exhibiting and building resilience (Tugade \& Frederickson, 2004; 2007), but humor appears to be a factor that does not easily transfer to the sport context. Collectively, these mixed findings suggest the need to further examine the relevance of 'humor' in relation to assessment of resilience in sport.

We concur with Gucciardi and colleagues' (2011) contention that the CD-RISC-10 assesses personal qualities linked with resilience but not resilience per se. Traditional views of resilience contain two elements, namely, the ability to experience adversity and the ability to cope or adapt positively to such adverse experiences (Luthar \& Cicchetti, 2000). The CD-RISC10 contains three items that assess the ability to experience adversity ("deal with whatever comes," "not easily discouraged by failure," and "can handle unpleasant feelings"). It also contains three items that tap into positive adaptation ("adapt to change," "coping with stress strengthens" and "bounce back after illness or hardship") (Gucciardi et al., 2011). Thus, 60\% of the instrument items tap into the components of resilience. The remaining items ("achieve goals," "see the humorous side of things," "under pressure focus and think clearly" and "think of self as a strong person") address qualities that might accompany resilience. No items capture the process of the experience of adversity plus positive coping. Thus, collectively the 10 items seem 
to resilient qualities and behaviors rather than resilience. Statistically our findings and those of Gucciardi and colleagues (2011) support the unidimensional nature of the construct. There remains, however, some questions related to the conceptual coherence of the measure.

Prior research established the age invariance of the CD-RISC-10 (Gucciardi et al, 2011). We found support for the gender invariance of the measure. The CD-RISC-10 passed both the weak and strong invariance tests. These findings suggest that responses to the CD-RISC-10 do not vary across genders. Previous use of the CD-RISC has not found differences between males and females, but this was only determined by a t-test in a small sample of male and female Iranian athletes (Hosseini \& Besharat, 2010). In sum, our findings relative to gender invariance suggest, importantly, that differences between the genders found at the latent level will be due to actual differences and not represent artifacts of measurement.

Findings related to the relationship between resilient qualities and predicted outcomes provided conceptual and validity support for the CD-RISC-10. Resilient qualities, as assessed with the CD-RISC-10, exhibited a moderate and positive relationship with positive affect and a moderate and negative relationship with negative affect. Thus, runners with resilient qualities are more likely to experience emotions such as excitement, enthusiasm, and interest. They are less likely to self-report being upset, distressed, and irritable. Our findings in relation to positive affect are logical given the conceptual importance of positive emotions in the resilience process (Tugade \& Fredrickson, 2004). Positive emotions play a key role in an individual's ability to bounce back from adversity.

The findings relative to negative affect are cause for a bit of concern. This is due the measurement issues that arose in negative affect subscale of the PANAS in the measurement model of the SEM. A number of negative items did not load on negative subscale. Our finding 
highlights the complexity of emotions in sport and how self-report assessments from general psychology (e.g., the PANAS) may not adequately translate to the sport context. For example, in this study the emotions that did not load on negative affect (ashamed, nervous, and afraid) may be interpreted in a facilitative way in the sport setting (Hanin, 1999). Emotion researchers in sport have documented that being nervous and fearful are often perceived as facilitative emotions that are used to prime athletes for competitions (Hanin, 1999). Simply categorizing emotions as negative or positive might be too simplistic for understanding emotional consequences of having resilient qualities. Further exploration of the negative emotional response pattern of athletes with resilient qualities is necessary to fully understand this issue.

We found that the CD-RISC negatively predicted performance anxiety. Specifically, the CD-RISC-10 inversely predicted somatic anxiety, cognitive anxiety, and concentration disruption. The relationships were weak to moderate with the strongest relationship emerging with worry (i.e. cognitive anxiety). Thus, runners with resilient qualities are less likely to experience body tension, shaky muscles, worry associated with not running well or letting down others, and are less apt to lose focus while running. Our findings support previous research (Fletcher \& Sarkar, 2012; Martin-Krumm, Sarrazin, Peterson, \& Famose, 2003) in relationship to resilience and competitive anxiety and stress. In general, resilient qualities may equip individuals with the ability to consistently approach competitive running events with generally less anxiety. Given that the sample had an average of just over 10 years of running experience, it is possible that many repetitions of running races and training provided these individuals confidence in their ability to handle demands both foreseen or unforeseen when competing. Indeed, previous experience is a predictor of developing resilience (Lepore \& Revenson, 2006) and this may have contributed to the relationship of resilience and anxiety observed herein. 
Several limitations should be noted. Our data was gathered online. While this is a very convenient method of data collection it is biased toward those with Internet access and it is possible that measurement error was inflated because we could not control or oversee survey completion. Our participants were runners with variable experience. Research thus far has examined the CD RISC in cricketers and runners. While examining team sport participants and individual sport participants is a plus, the total number and variety of samples examined in the literature remains quite low.

In summary, our findings, in combination those of Gucciardi and colleagues (2011), suggest that the CD-RISC-10 is a valid and reliable instrument in the sport setting. The CDRISC-10 exhibited a strong factor structure and gender invariance, was internally reliable, and predicted both affect and anxiety in the expected directions. We concur with Gucciardi et al. (2011) in recommending it be used to assess resilient qualities and not resilience in sport. 


\section{References}

Ahern, N. R., Kiehl, E. M., Sole, M. L., \& Byers, J. (2006). A review of instruments measuring resilience. Issues in Comprehensive Pediatric Nursing, 29,103-125. doi:10.1080/01460860600677643

Bentler, P. M. (2007). On tests and indices for evaluating structural models. Personality and Individual Differences, 42, 825-829.

Block, J. H., \& Block, J. (1980). The role of ego-control and ego-resiliency in the organization of behavior. In W. A. Collins (Ed.), The Minnesota Symposia on child psychology (Vol. 13, pp. 39-101). Hillsdale, NJ: Erlbaum.

Bonanno, G. (2004). Loss, trauma, and human resilience: Have we underestimated the human capacity to thrive after extremely aversive events? American Psychologist, 59, 20-28. doi:10.1037/0003-066X.59.1.20

Burns, R. A., \& Anstey, K. J. (2010). The Connor-Davidson Resilience Scale (CD-RISC): Testing the invariance of a uni-dimensional resilience measure that is independent of positive and negative affect. Personality and Individual Differences, 48, 527-531. doi:10.1016/j.paid.2009.11.026.

Campbell-Sills L, Stein MB. (2007) Psychometric analysis and refinement of the ConnorDavidson Resilience Scale (CD-RISC): Validation of a 10-item measure of resilience. Journal of Trauma Stress, 20, 1019-1028.

Connor, K. M., \& Davidson, J. R. T. (2003). Development of a new resilience scale: The Connor-Davidson Resilience Scale (CD-RISC). Depression and Anxiety, 18, 76-82. doi:10.1002/da.10113

Davidson, J. R., Payne, V. M., Connor, K. M., Foa, E. B., Rothbaum, B. O., Hertzberg, M. A., et 
al. (2005). Trauma, resilience, and saliostatis: Effects of treatment on posttraumatic stress disorder. International Clinical Psychopharmacology, 20, 43-48.

Fletcher, D. \& Sarkar, M. (2012). A grounded theory of psychological resilience in Olympic champions, Psychology of Sport and Exercise, 13, 669-678. doi:10.1016/j.psychsport.2012.04.007.

Galli, N. \& Vealey, R. S. (2008). "Bouncing back" from adversity: Athletes' experiences of resilience. The Sport Psychologist, 22, 316-335. Retrieved from http://journals.humankinetics.com/tsp

Galli, N. \& Gonzalez, S. P. (2014). Psychological resilience in sport: A review of the literature and implications for research and practice. International Journal of Sport and Exercise Psychology. doi:10.1080/1612197X.2014.946947

Gucciardi, D. F., Jackson, B., Coulter, T. J., \& Mallett, C. J. (2011). The Connor-Davidson Resilience Scale (CD-RISC): Dimensionality and age-related measurement invariance with Australian cricketers. Psychology of Sport and Exercise, 12, 423-433. doi:10.1016/j.psychsport.2011.02.005

Hanin, Y. (1999). Emotions in sport. Champaign, IL: Human Kinetics.

Hofmann, R. (1995). Establishing factor validity using variable reduction in confirmatory factor analysis. Educational and Psychological Measurement, 55, 572-582.

Hosseini, S. A., \& Besharat, M. A. (2010). Relation of resilience with sport achievement and mental health in a sample of athletes. Procedia Social and Behavioral Sciences, 5, 633638. doi:10.1016/j.sbspro.2010.07.156

Hu, L., \&Bentler, P.M. (1998). Fit indices in covariance structure modeling: Sensitivity to underparameterization model misspecification. Psychological Methods, 3, 424-453. 
Hu \& Bentler, P.M. (1999). Cutoff criteria for fit indexes in covariance structure analysis: Coventional criteria versus new alternatives. Structural Equation Modeling, 6, 1-55. Kline, R. B. (2011). Principles and practice of structural equation modeling (3rd ed.). New York, NY: Guilford Press.

Kobasa, S. C. (1979). Stressful life events, personality, and health: An inquiry into hardiness. Journal of Personality and Social Psychology, 37, 1-11.

Kumpfer, K. L. (1999). Factors and processes contributing to resilience: The resilience framework. In M. D. Glantz \& J. L. Johnson (Eds.), Resilience and development: Positive life adaptions (pp. 179-224). New York: Kluwer Academic/Plenum.

Lepore, S. J., \& Revenson, T. A. (2006). Resilience and posttraumatic growth: Recovery, resistance, \& reconfiguration. In L. Calhoun \& R. G. Tedeschi (Eds.), The Handbook of Posttraumatic Growth: Research and Practice (pp. 24-46). Mahwah, NJ: Erlbaum.

Luthar, S. S., \& Cicchetti, D. (2000). The construct of resilience: Implications for interventions and social policies. Development and Psychopathology, 12, 857-885. Retrieved from http://journals.cambridge.org/action/displayAbstract;jsessionid=2273EB2B8638A4D2E5 0FA35FC1AE2A3F.journals?fromPage $=$ online $\&$ aid $=62557$

Lyons, J. (1991). Strategies for assessing the potential for positive adjustment following trauma. Journal of Traumatic Stress, 4, 93-111.

Martin-Krumm, C. P., Sarrazin, P. G., Peterson, C., \& Famose, J. (2003). Explanatory style and resilience after sports failure. Personality and Individual Differences, 35, 1685-1695. doi:10.1016/j.paid.2004.09.023

Masten, A. (2001). Ordinary magic. American Psychologist, 56, 227- 238. doi:10.1037//0003-066X.56.3.227 
Nunnally, J. C. (1978). Psychometric theory (2nd ed.). New York: McGraw-Hill.

Mauss, I. B., \& Robinson, M. D. (2009). Measures of emotion: A review. Cognitive Emotion, 23, 209-237. doi:10.1080/02699930802204677

Muthen \& Muthen, (2014) http://www.statmodel.com/

Rutter, M. (1985). Resilience in the face of adversity: Protective factors and resistance to psychiatric disorders. British Journal of Psychology, 147, 598-611.

Smith, R. E., Smoll, F. L., Cumming, S. P., \& Brossbard, J. R. (2006). Measurement of multidimensional sport performance anxiety in children and adults: The Sport Anxiety Scale-2. Journal of Sport and Exercise Psychology, 28, 479-501. Retrieved from http://journals.humankinetics.com/jsep

Southwick, S. M., Ozbay, F., Chaney, D., \& McEwen, B. S. (2008). Adaption to stress and psychobiological mechanisms of resilience. In B. J. Lukey \& V. Tepe (Eds.), Biobehavioral Resilience to Stress (pp. 91-115). Boca Raton, FL: CRC Press.

Tabachnick, B. G., \& Fidell, L.S. (2007). Using Multivariate Statistics (5th ed.). Boston: Allyn \& Bacon.

Tugade, M. M., \& Frederickson, B. L. (2007). Regulation of positive emotions: Emotion regulation strategies that promote resilience. Journal of Happiness Studies, 8, 311-333. doi:10.1037/002-3514.862520

Watson, D., Clark, L. A., \& Tellegen, A. (1988). Development and validation of brief measures of positive and negative affect: The PANAS scales. Journal of Personality and Social Psychology, 54(6), 1063-1070. doi:10.1037/0022-3514.54.6.1063

Waugh, C. E., Tugade, M. M., \& Fredrickson, B. L. (2008). Psychophysiology of stress and resilience. In: B. Lukey \& V. Tepe (Eds.), Biobehavioral Resilience to Stress (pp. 117- 
138). Boca Raton, FL: CRC Press.

Windle, G., Bennett, K. M., \& Noyes, J. (2011). A methodological review of resilience measurement scales. Health \& Quality of Life Outcomes, 9, 8-25. doi:10.1186/14777525-9-8 
Table 1.

Means, Standard Deviations, Cronbach's Alphas, and Pearson Product Correlations Among Major Measures.

\begin{tabular}{|c|c|c|c|c|c|c|c|c|c|c|c|c|}
\hline Measures & 1 & 2 & 3 & 4 & 5 & 6 & 7 & 8 & 9 & 10 & 11 & 12 \\
\hline $\begin{array}{l}\text { CD-RISC 5- Factor Scale } \\
\text { 1. CD-RISC Factor } 1 \\
\text { (Competence) }\end{array}$ & ----- & & & & & & & & & & & \\
\hline $\begin{array}{l}\text { 2. CD-RISC Factor } 2 \\
\text { (Strengthening effect of stress) }\end{array}$ & $.67^{* *}$ & ----- & & & & & & & & & & \\
\hline $\begin{array}{l}\text { 3. CD-RISC Factor } 3 \\
\text { (Positive acceptance of change) }\end{array}$ & $.69 * *$ & $.67 * *$ & ----- & & & & & & & & & \\
\hline $\begin{array}{l}\text { 4. CD-RISC Factor } 4 \\
\text { (Perceptions of Control) }\end{array}$ & $.62 * *$ & $.52 * *$ & $.54^{* *}$ & ----- & & & & & & & & \\
\hline $\begin{array}{l}\text { 5. CD-RISC Factor } 5 \\
\text { (Spirituality) }\end{array}$ & $.16^{* *}$ & .05 & $.14 * *$ & $.32 * *$ & ----- & & & & & & & \\
\hline 6. CD-RISC 25-item Scale & $.88 * *$ & $.84^{* *}$ & $.82^{* *}$ & $.77^{* *}$ & $.36^{* *}$ & ---- & & & & & & \\
\hline 7. CD-RISC-10-item Scale & $.81 * *$ & $.90 * *$ & $.84^{* *}$ & $.57 * *$ & .05 & $.90 * *$ & ---- & & & & & \\
\hline 8. Positive Affect & $.40 * *$ & $.20 * *$ & $.26^{* *}$ & $.24 * *$ & $.20^{* *}$ & $.33^{* *}$ & $.67 * *$ & ----- & & & & \\
\hline 9. Negative Affect & $.19 * *$ & .02 & .10 & .03 & .10 & $.13^{*}$ & .08 & $.26^{* *}$ & ---- & & & \\
\hline 10. Somatic & $-.13 * *$ & $-.21 * *$ & $-.12 *$ & $-.13 * *$ & -.03 & $-.14 * *$ & $-.21 * *$ & $.17^{* *}$ & $.42^{* *}$ & ---- & & \\
\hline 11. Worry & $-.19 * *$ & $-.24 * *$ & $-.24 * *$ & $-.26 * *$ & -.02 & $-.21 * *$ & $-.29 * *$ & $.17^{* *}$ & $.38^{* *}$ & $.52^{* *}$ & ---- & \\
\hline 12. Concentration & $-.30 * *$ & $-.25 * *$ & $-.34 * *$ & $-.27 * *$ & -.01 & $-.27 * *$ & $-.34 * *$ & .04 & $.21^{* *}$ & $.42 * *$ & $.50^{* *}$ & ---- \\
\hline Mean & 26.45 & 20.57 & 16.41 & 9.27 & 5.18 & 78.12 & 31.14 & 31.52 & 26.36 & 9.20 & 9.51 & 6.54 \\
\hline Standard Deviation & 3.80 & 3.80 & 2.53 & 2.06 & 2.28 & 10.91 & 5.08 & 3.85 & 3.89 & 2.80 & 3.39 & 1.85 \\
\hline Cronbach's Alpha & .84 & .78 & .75 & .72 & .67 & .89 & .87 & .69 & .65 & .82 & .91 & .77 \\
\hline
\end{tabular}

Note: ** Correlations are significant at $p<.01 . *$ Correlations are significant at $p<.05$. Shaded area reflects CD-RISC-10-item scale and correlations amongst other constructs. 
Table 2

Goodness of fit indices for the three CD-RISC models and Gender Invariance of the 10-item CD-RISC.

\begin{tabular}{|c|c|c|c|c|c|c|c|}
\hline Model & $\chi^{2}$ & $d f$ & $p$ & RMSEA(90\%) & SRMR & CFI & TLI \\
\hline Original 5-Factor CD-RISC & 837.615 & 265 & $<.001$ & $.073(.068-.097)$ & .064 & .838 & .816 \\
\hline Unidimensional 25-item CD-RISC & 1150.411 & 275 & $<.001$ & $.089(.083-.094)$ & .075 & .752 & .729 \\
\hline Unidimensional 10-item CD-RISC & 69.446 & 35 & .005 & $.049(.032-.066)$ & .032 & .971 & .963 \\
\hline Gender Invariance Testing & $\chi^{2}$ & $d f$ & $p$ & RMSEA $(90 \%)$ & SRMR & CFI & TLI \\
\hline Configural Two Group & 2094.247 & 1368 & $<.001$ & $.052(.047-.056)$ & .080 & .909 & .866 \\
\hline
\end{tabular}

Note: Residual error terms were not correlated. RMSEA is the Root Mean Square Error of Approximation, SRMR is the Standardized Root Mean Square Residual, CFI is the Comparative Fit Index, and TLI is the Tucker Lewis Index. 
Table 3

Standardized factor loadings $(\lambda)$ and error terms $(\theta)$ of the three CD-RISC models using fixed factor method.

\begin{tabular}{|c|c|c|c|c|c|c|}
\hline \multirow[b]{2}{*}{ CD-RISC Items } & \multicolumn{2}{|c|}{ Model 1} & \multicolumn{2}{|c|}{ Model 2} & \multicolumn{2}{|c|}{ Model 3} \\
\hline & $\bar{\lambda}$ & $\Theta$ & $\lambda$ & $\Theta$ & $\lambda$ & $\Theta$ \\
\hline 1. Adapt to change & .595 & .037 & .542 & .037 & .599 & .036 \\
\hline 2. Close and secure relationships & .390 & .047 & .394 & .044 & ---- & ---- \\
\hline 3. Sometimes fate or god can help & .661 & .061 & .071 & .052 & ---- & ---- \\
\hline 4. Can deal with whatever comes & .719 & .030 & .655 & .031 & .701 & .030 \\
\hline 5. Past success gives confidence for new challenge & .656 & .034 & .605 & .034 & ---- & ---- \\
\hline 6. See humorous side of things & .448 & .044 & .416 & .044 & .459 & .043 \\
\hline 7. Coping with stress strengthens & .565 & .038 & .559 & .036 & .589 & .037 \\
\hline 8. Tend to bounce back after illness or hardship & .606 & .036 & .573 & .036 & .580 & .037 \\
\hline 9. Things happen for a reason & .780 & .067 & .202 & .050 & --- & ---- \\
\hline 10. Best effort no matter what & .552 & .039 & .511 & .039 & --- & ---- \\
\hline 11. You can achieve your goals & .653 & .033 & .621 & .033 & .549 & .039 \\
\hline 12. When things look hopeless, I don't give up & .656 & .033 & .617 & .033 & --- & ---- \\
\hline 13. Know where to turn for help & .582 & .040 & .476 & .041 & --- & ---- \\
\hline 14. Under pressure, focus and think clearly & .723 & .028 & .673 & .030 & .694 & .030 \\
\hline 15. Prefer to take the lead in problem-solving & .603 & .036 & .561 & .036 & --- & ---- \\
\hline 16. Not easily discouraged by failure & .603 & .035 & .603 & .034 & .588 & .037 \\
\hline 17. Think of self as strong person & .770 & .025 & .772 & .023 & .731 & .028 \\
\hline 18. Make unpopular or difficult decisions & .657 & .033 & .587 & .035 & --- & ---- \\
\hline 19. Can handle unpleasant feelings & .667 & .032 & .610 & .034 & .656 & .033 \\
\hline 20. Have to act on a hunch & .351 & .048 & .374 & .045 & --- & ---- \\
\hline 21. Strong sense of purpose & .759 & .032 & .564 & .036 & --- & ---- \\
\hline 22. In control of your life & .688 & .035 & .625 & .033 & --- & ---- \\
\hline 23. I like challenges & .686 & .030 & .671 & .030 & --- & ---- \\
\hline 24. You work to attain your goals & .353 & .047 & .312 & .047 & --- & ---- \\
\hline 25. Pride in your achievements & .454 & .043 & .420 & .043 & ---- & ---- \\
\hline
\end{tabular}

Note: Model 1: Original 5-Factor CD-RISC, Model 2: Unidimensional 25-item CD-RISC, \& Model 3: Unidimensional 10-item CD-RISC. 


\section{Table 4}

Item statistics for the CD-RISC-10-item model of resilience.

\begin{tabular}{|c|c|c|c|c|c|c|}
\hline CD-RISC-10 Items & Mean & S.D. & Skewness & Kurtosis & $\begin{array}{c}\text { Corrected } \\
\text { Item-Total } \\
\text { Correlation } \\
\end{array}$ & $\begin{array}{c}\text { Alpha if } \\
\text { Item } \\
\text { Deleted }\end{array}$ \\
\hline Adapt to change & 3.03 & .71 & -.53 & 1.04 & .57 & .85 \\
\hline Can deal with whatever comes & 3.26 & .71 & -.50 & -.51 & .66 & .85 \\
\hline $\begin{array}{l}\text { Tries to see humorous side of } \\
\text { problems }\end{array}$ & 3.10 & .84 & -.57 & -.45 & .46 & .86 \\
\hline $\begin{array}{l}\text { Coping with stress can } \\
\text { strengthen me }\end{array}$ & 3.05 & .78 & -.46 & -.14 & .55 & .86 \\
\hline $\begin{array}{l}\text { Tend to bounce back after } \\
\text { illness of hardship }\end{array}$ & 3.27 & .71 & -.72 & .32 & .55 & .86 \\
\hline $\begin{array}{l}\text { Can achieve goals despite } \\
\text { obstacles }\end{array}$ & 3.36 & .65 & -.72 & .44 & .53 & .86 \\
\hline $\begin{array}{l}\text { Can stay focused under } \\
\text { pressure }\end{array}$ & 2.97 & .73 & -.09 & -.67 & .66 & .85 \\
\hline $\begin{array}{l}\text { Not easily discouraged by } \\
\text { failure }\end{array}$ & 2.89 & .85 & -.50 & .27 & .55 & .86 \\
\hline $\begin{array}{l}\text { Thinks of self as a strong } \\
\text { person }\end{array}$ & 3.28 & .73 & -.79 & .24 & .68 & .84 \\
\hline Can handle unpleasant feelings & 2.93 & .82 & -.61 & .39 & .62 & .85 \\
\hline
\end{tabular}

Note: Full 10-item CD-RISC Cronbach's alpha $=.87$. 
Table 5.

SEM Standardized Loadings for All Measures and Regression Weights for Resiliency to Somatic Anxiety, Worry, Concentration Disruption, Positive Affect, and Negative Affect.

\begin{tabular}{|c|c|c|}
\hline Scale and Items & $\begin{array}{l}\text { Loadings } \\
\text { (Female/Male) }\end{array}$ & $\mathbf{R}$ \\
\hline Somatic Anxiety & & -.24 \\
\hline My body feels tense. & $0.65 / 0.66$ & \\
\hline I feel tense in my stomach. & $0.67 / 0.60$ & \\
\hline My muscles feel shaky. & $0.66 / 0.69$ & \\
\hline My stomach feels upset. & $0.62 / 0.55$ & \\
\hline My muscles feel tight because I am nervous. & $0.75 / 0.75$ & \\
\hline Worry & & -.58 \\
\hline I worry that I will not play well. & $0.86 / 0.82$ & \\
\hline I worry I will let others down. & $0.65 / 0.62$ & \\
\hline I worry I will not play my best. & $0.90 / 0.91$ & \\
\hline I worry that I will play badly. & $0.92 / 0.91$ & \\
\hline I worry that I will mess up during the game. & $0.79 / 0.80$ & \\
\hline Concentration Disruption & & -.38 \\
\hline It is hard to concentrate on the game. & $0.59 / 0.54$ & \\
\hline It is hard for me to focus on what I am supposed to do & $0.68 / 0.68$ & \\
\hline I lose focus on the game. & $0.60 / 0.68$ & \\
\hline I cannot think clearly during the race. & $0.69 / 0.70$ & \\
\hline I have a hard time focusing on what my coach tells me. & $0.64 / 0.68$ & \\
\hline Positive Affect & & .67 \\
\hline Interested. & $0.69 / 0.76$ & \\
\hline Excited. & $0.74 / 0.75$ & \\
\hline Strong. & $0.55 / 0.55$ & \\
\hline Enthusiastic. & $\# 9=-0.27 /-0.04$ & \\
\hline Proud. & $0.80 / 0.80$ & \\
\hline Alert. & $\# 12=-0.26 /-0.0$ & \\
\hline Inspired. & $\# 14=-0.19 /-0.1$ & \\
\hline Determined. & $0.64 / 0.71$ & \\
\hline Attentive. & $0.64 / 0.62$ & \\
\hline Active. & $0.65 / 0.61$ & \\
\hline Negative Affect & & -.57 \\
\hline Distressed. & $0.63 / 0.73$ & \\
\hline Upset. & $0.70 / 0.69$ & \\
\hline Guilty. & $0.70 / 0.70$ & \\
\hline Scared. & $0.27 / 0.34$ & \\
\hline Hostile. & $0.46 / 0.55$ & \\
\hline Irritable. & $0.67 / 0.62$ & \\
\hline Interested. & $0.20 / 0.32$ & \\
\hline Resilience (formative construct) & & N/A \\
\hline Adapt to change. & $0.60 / 0.63$ & \\
\hline Can deal with whatever comes. & $0.69 / 0.70$ & \\
\hline See humorous side of things. & $0.44 / 0.49$ & \\
\hline Coping with stress strengthens. & $0.57 / 0.59$ & \\
\hline Tend to bounce back after illness/hardship. & $0.58 / 0.65$ & \\
\hline You can achieve your goals. & $0.55 / 0.57$ & \\
\hline Under pressure, focus and think clearly. & $0.72 / 0.68$ & \\
\hline Not easily discouraged by failure. & $0.57 / 0.64$ & \\
\hline Think of self as strong person. & $0.73 / 0.71$ & \\
\hline Can handle unpleasant feelings. & $0.64 / 0.68$ & \\
\hline
\end{tabular}

Note: Fit Statistics for the Structural Equation Model $(\mathrm{SEM}): \chi^{2}=3491.48 ; \mathrm{df}=933 ; p=.001 ; \mathrm{NFI}=.96$; $\mathrm{IFI}=.97 ; \mathrm{CFI}=.69 ; \mathrm{GFI}=.97 ; \mathrm{TLI}=.67 ; \mathrm{RMSEA}=.08 ; \mathrm{SRMSR}=.14 ; \mathrm{R}^{2}=76 \%$. 
Figure 1.

Sport Resilience Model (SRM)

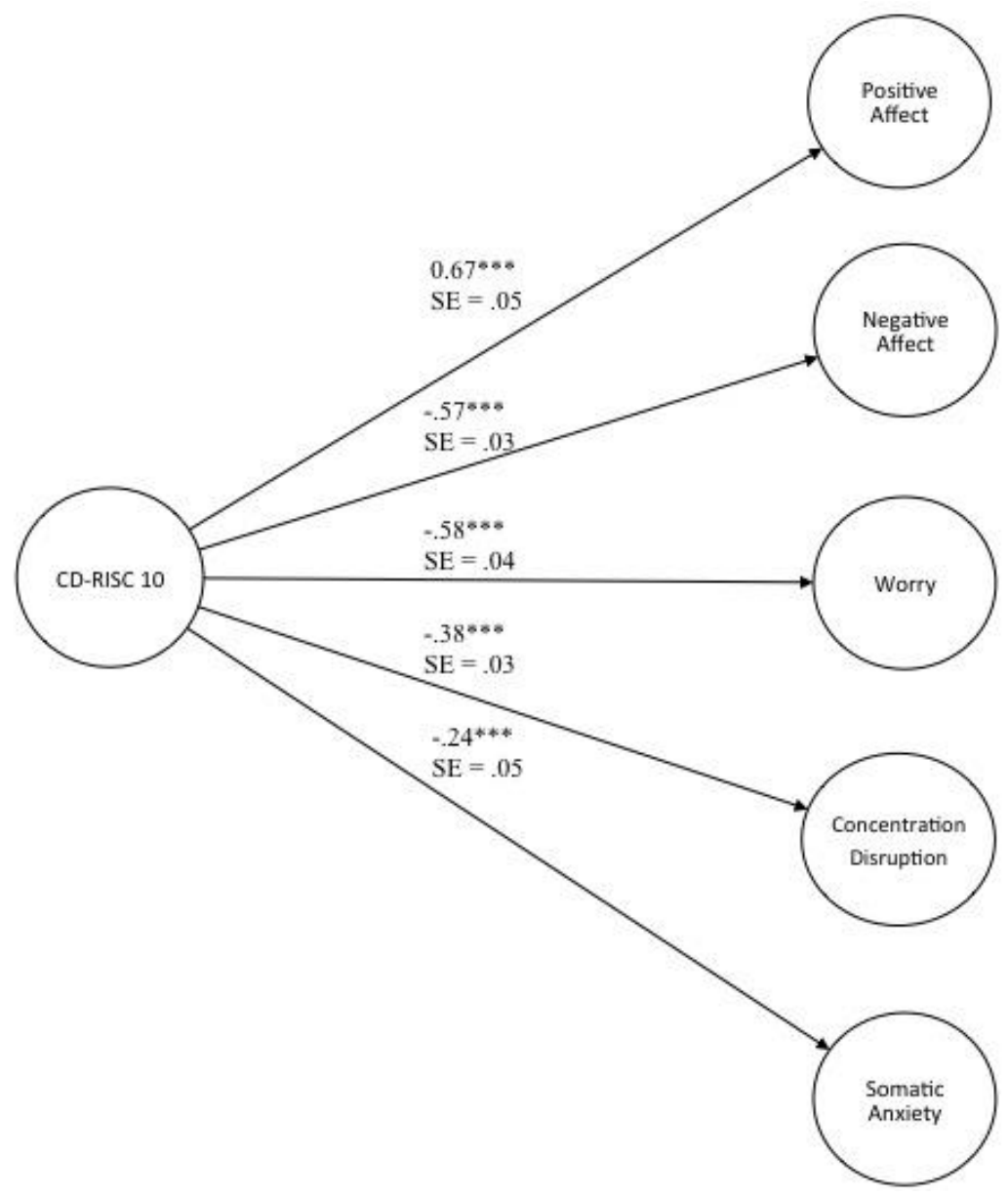

